\title{
Influence of geometrical parameters of convergent sleeve on the value of limit stress
}

\author{
Jan Górecki ${ }^{1,{ }^{*}}$, Ireneusz Malujda ${ }^{1}$, Krzysztof Talaśka ${ }^{1}$, Dominik Wilczyński ${ }^{1}$, \\ Dominik Wojtkowiak ${ }^{1}$ \\ ${ }^{1}$ Chair of Basic Machines Design, Poznan University of Technology, ul. Piotrowo 3, Poznan, Poland
}

\begin{abstract}
This paper presents the results of research on improving the effectiveness of the agglomeration process. Improving effectiveness was obtained as a result of the application of the convergent sleeve. The sleeve is mounted before the multi-holes die in the dry ice agglomeration machine. The empirical part of the paper presents the results of research on which FEM model was based. The numerical part of research presents the FEM model of the agglomeration process. The FEM model with a known uncertainty level was used to determine the influence of geometrical parameters of the sleeve on the limit value of the agglomeration forces. The model will be one of the starting points for the design and construction of the machine for the compaction and granulation of dry ice.
\end{abstract}

Keywords: dry ice, convergent sleeve, compaction, densification

\section{Introduction}

The by-products of manufacturing processes can be reused, for example as raw material. One material that undergoes the recovery process is carbon dioxide, which is a waste, for example, in the production process of ammonia compounds [1]. This process has the highest percentage share compared with other sources of $\mathrm{CO}_{2}$ emissions (fig. 1). This gas can be compressed, resulting in its condensation, and in this form it is stored for further use. However, due to the large amounts of recycled waste material, plants very often have a problem with its full management. Therefore, liquid carbon dioxide is supplied to interested recipients [1-3].

Liquefied carbon dioxide, subjected to decompression, undergoes crystallization $[4,5]$. The resulting product has temperature of $-78.5{ }^{\circ} \mathrm{C}$ and sublimes under the surrounding conditions $[1,6-8]$. Due to its special properties, it has been commonly called dry ice. Both maintaining low temperature and sublimation in standard conditions make the material widely used in the food industry, e.g. in the process of water carbonation, cleaning and disinfecting surfaces or as an input to refrigerated containers [4-6, 8-14].

\footnotetext{
* Corresponding author: jan.gorecki@put.poznan.pl

Reviewers: Marek Macko, Wiesława Piekarska
} 


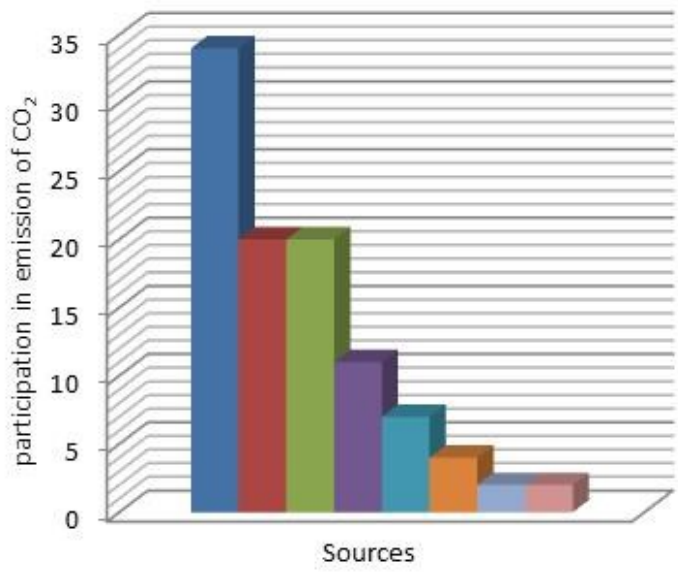

Ammonia production

- Oil and gas refineries

- Geological formations

Ethanol production

- Chemical manufacturing

Flue gas and cogeneration

Alcohol production

athers

Fig. 1. Percentage breakdown of major sources of $\mathrm{CO}_{2}$ emissions [12]

Agglomeration of crystallized carbon dioxide is performed in order to reduce its volume and extend the time of sublimation. Once compacted, it stays in the solid phase for longer, which affects the efficiency of its use for cooling purposes $[1,6,15,16]$.

The design of the piston working unit of the dry ice compaction machine is very often based on the systems with hydraulic or crank-piston drives (fig. 2) [17]. The review of the available literature does not provide sufficient information that would make it possible to perform a detailed analysis of the process of dry ice agglomeration. It is necessary for the assessment of such a process and in order to propose new technical solutions directed at its efficiency.

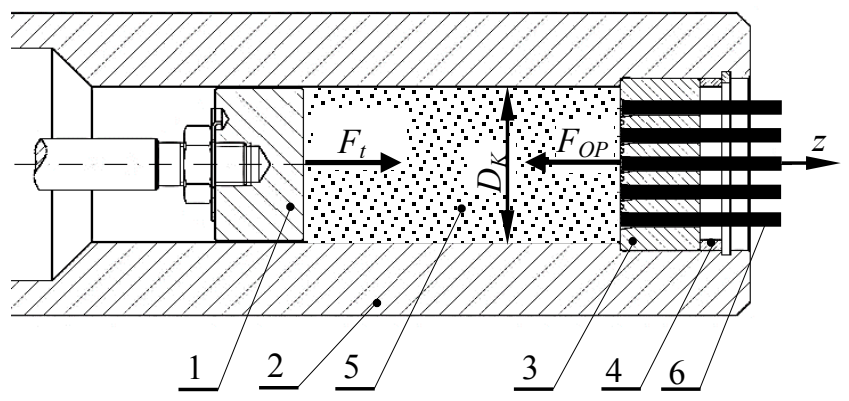

Fig. 2. Pressure agglomeration unit in piston technology. 1 - piston, 2 - cylindrical sleeve, 3 - multiholes die, 4 - spacer sleeve, 5 - crystallized carbon dioxide, 6 - compacted dry ice

The limit force on the compacting piston necessary for the execution of the agglomeration process is the value of the drag force $F_{O P}$ pushing the material through the multi-holes die (fig. 2, 3).

The value of $F_{O P}$ changes in the function of the geometric parameters of the die. One of the properties that affect the value of this force is the surface area $S_{P P}$. In order to reduce the indicated area, it was proposed in the patent application P.419432 that the working unit is equipped with the convergent sleeve. The element is mounted on the input surface of the die, through which the agglomerated material is injected (fig. 4). The position of the element in the example working unit is presented in fig. 4 


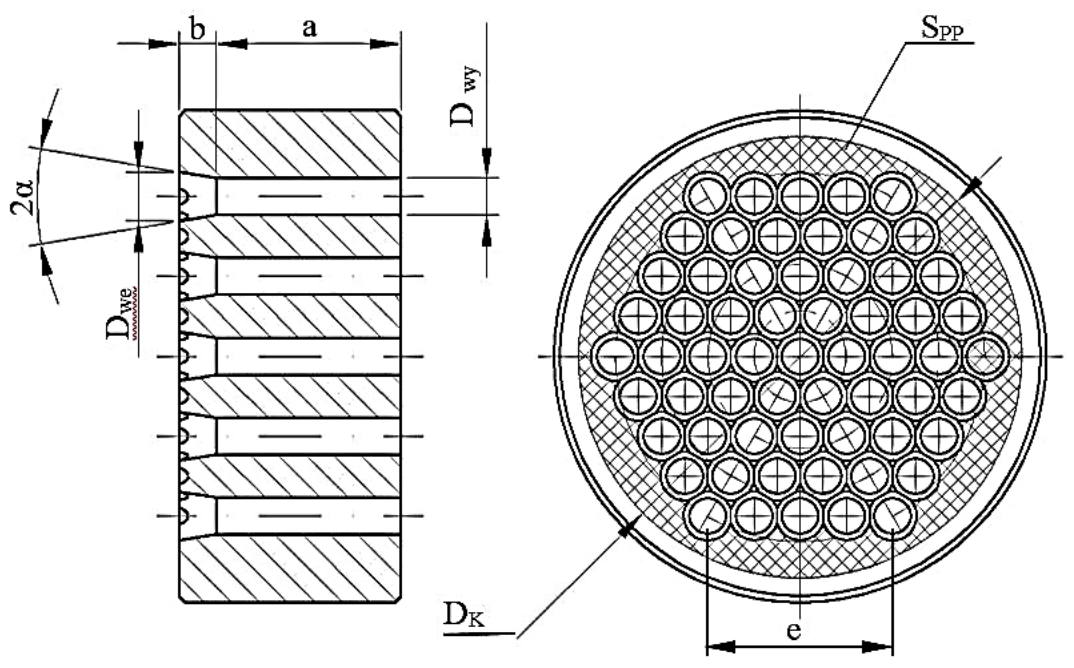

Fig. 3. Multi-holes die, $D_{w e}$ - input diameter of the forming channel, $D_{w y}-$ output diameter of the forming channel, $a$ - length of the cylindrical segment, $b$ - length of the conical segment , $2 \alpha-$ convergence angle of the conical segment, $\mathrm{D}_{\mathrm{K}}$ - working chamber diameter,

$\mathrm{S}_{\mathrm{PP}}-$ resistance surface area

a)

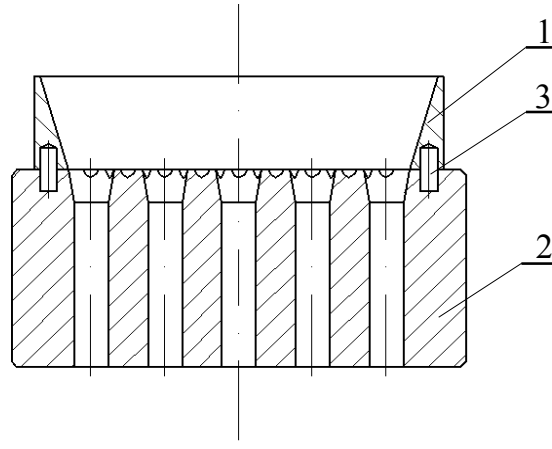

b)
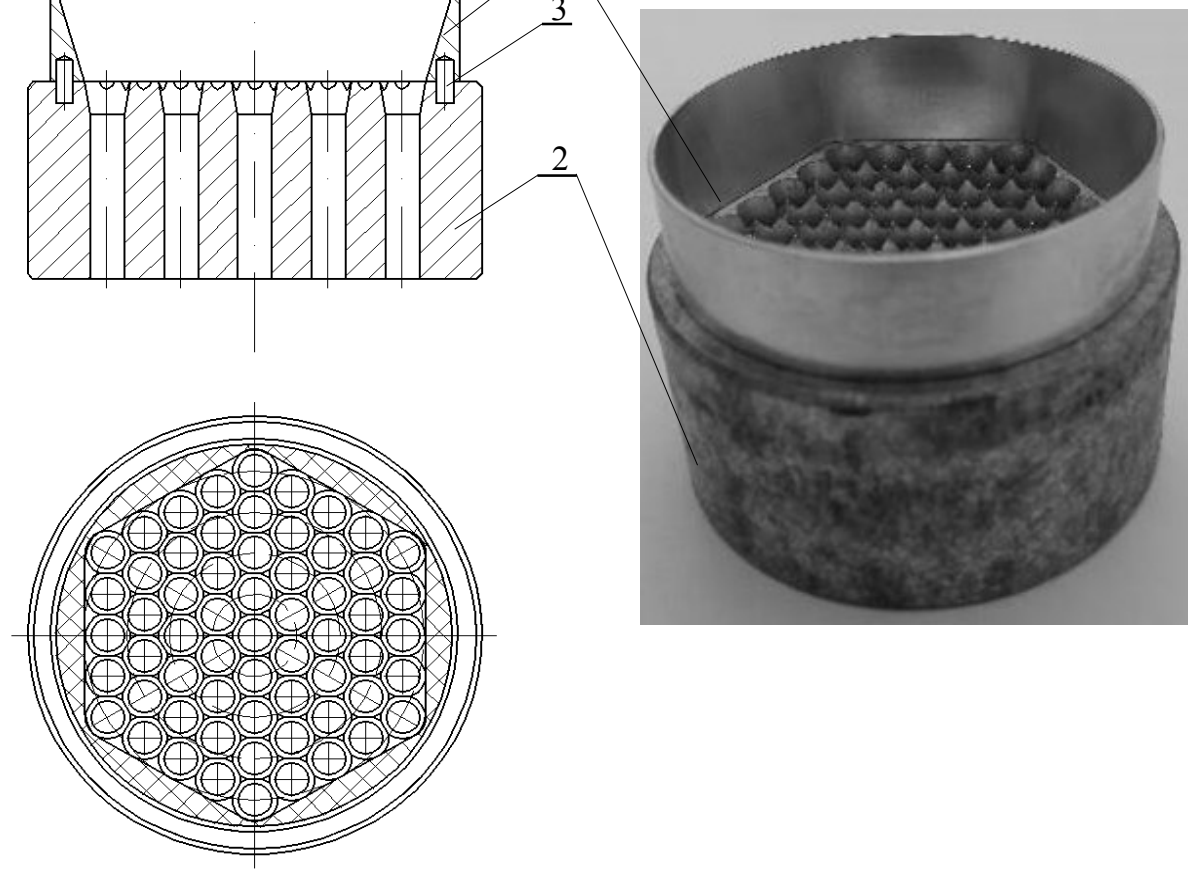

Fig. 4. Multi-holes die system with the convergent sleeve: a) system, b) stress condensing sleeve 1 stress condensing sleeve, 2 - multi-holes die, 3 - dowel pin 
Due to the non-circular symmetric shape of the sleeve, resulting from the transition from a round section to a hexagonal section, it was necessary to determine the relative positions of elements relative to each other using 2 dowel pins (3) (fig. 4).

The system assembled in such a way, with determined mutual positioning of the elements, can be mounted in the channel compacting crystallized carbon dioxide in crankpiston technology (fig. 5).

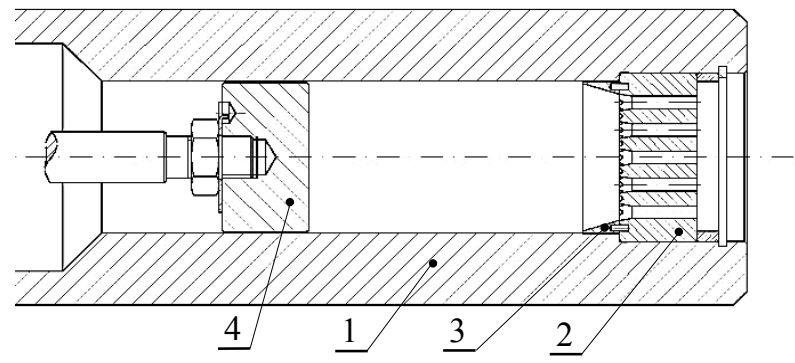

Fig. 5. The working unit of the agglomerating machine in piston technology: 1 - cylindrical sleeve, 2 - multi-holes die, 3 - convergent sleeve 4 - piston [18].

FEM analysis will be performed in this work in order to determine the impact of the application of the convergence sleeve to the value of the resistance force $F_{O P}$. The FEM model was based on the results of the empirical research. The model formulated in this way will be used to compare the effect of geometric parameters of the sleeve on the value of limit stress in the dry ice agglomeration process for sleeves of different heights $h$ (fig. 6).
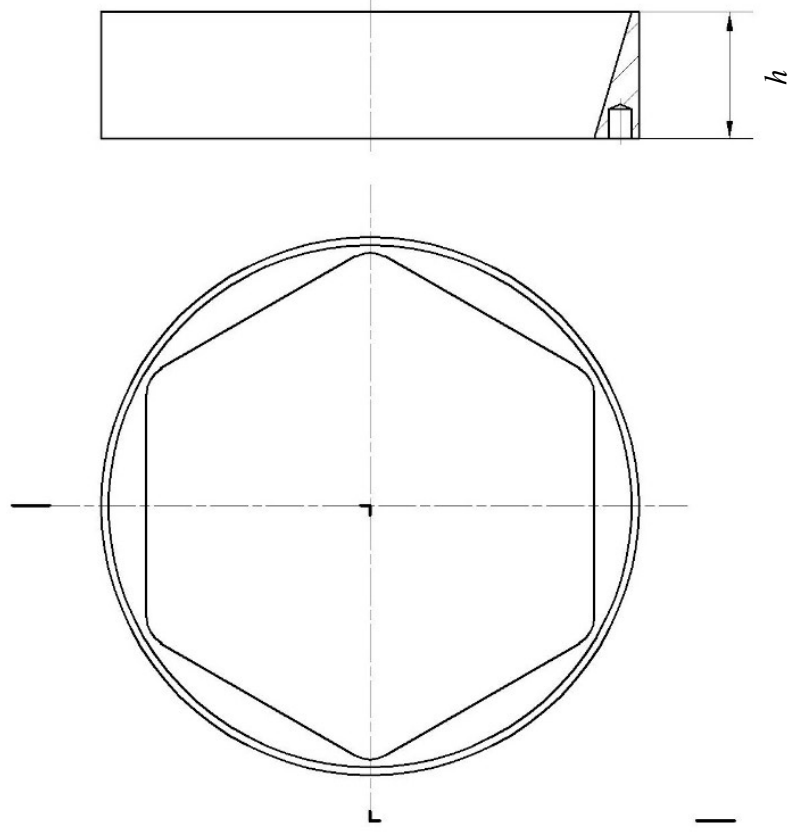

Fig. 6. Convergent sleeve [18] 


\section{Empirical research}

In order to determine the force on the piston $F_{t}$, necessary to carry out the process of agglomeration of crystallized carbon dioxide, the study has been performed in accordance with the methodology set out in the literature $[1,9,16]$. For this purpose, the MTS machine Insight $50 \mathrm{kN}$ has been used, recording values of the force and the displacement of the measuring head with $10 \mathrm{~Hz}$ frequency.

A special compaction head has been used to perform research (fig. 7). In order to reduce the measurement error resulting from the possibility of non-axial mounting of the compaction head, the clamps of the MTS machine have been equipped with the system for retaining perpendicularity of the compaction force relative to the specimen cross section (5).

Before the study, the compaction chamber (1) was filled with crushed dry ice. Then the stamp was inserted (3) into the compaction chamber (2). In the final stage, the head was mounted in the clamps of the MTS machine. After tarring the machine, the experiment started, during which the piston (3) was moved down at a constant speed. Once the value of the force $F_{t}$ became equal to the value of the force $F_{O P}$, the material was pressed through the multi-holes die (4).

a)

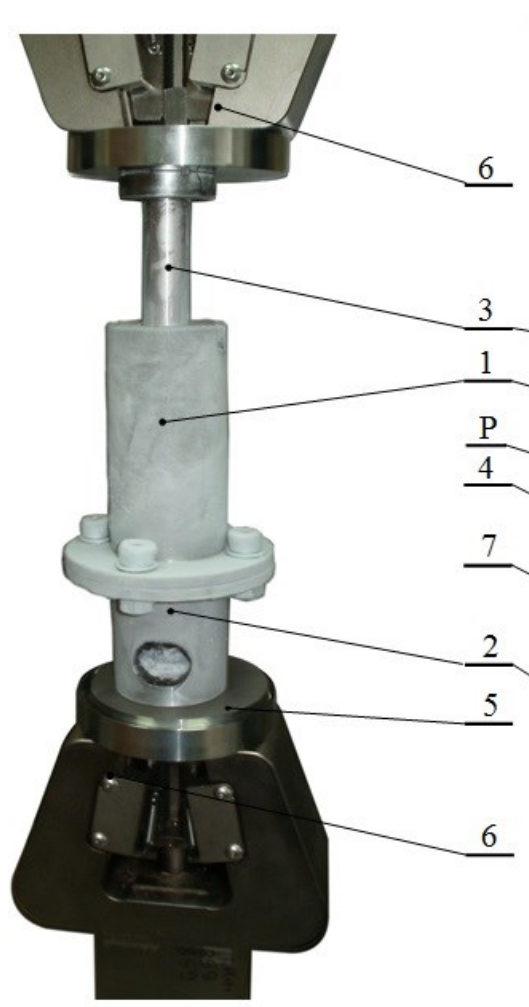

b)

) 
The research was conducted in 10 repetitions, which were averaged and presented in the form of compaction characterization describing the change of the force $F_{T}$ in the function of displacement $z$ (fig. 8).

The average value of the force $F_{O P}$ has been determined at $24.1 \mathrm{kN}$. It should be noted that this value is lower than the one determined in the studies reported in the literature for the identical multi-holes die [15].

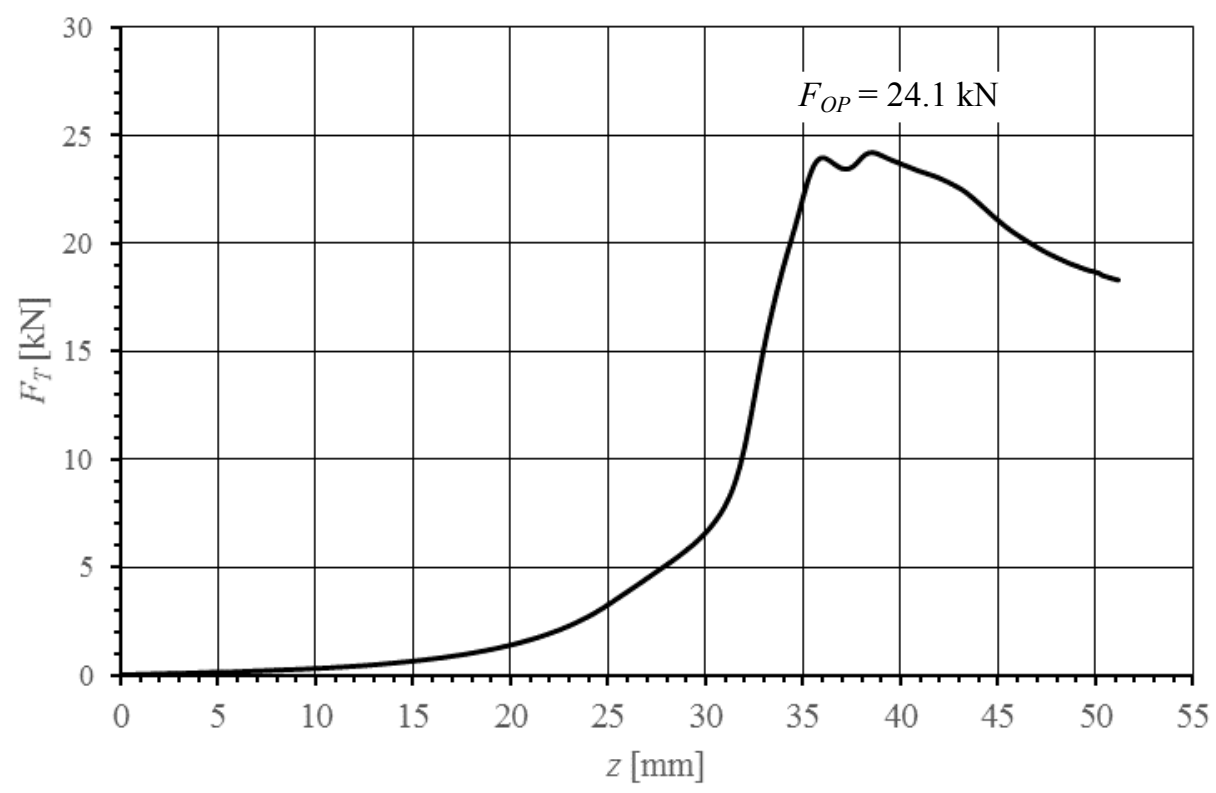

Fig. 8. Compaction characterization using the system of multi-holes die and convergent sleeve.

\section{FEM Model}

Figure 9 shows sample results of the analysis of pumping pre-compacted crystallized carbon dioxide. In the FEM model, piston 1 and die 2 have been modelled as rigid. The basis for this simplification is the fact that the material they are made of is many times stiffer than the material being pressed. The process of agglomeration can be divided into two phases. The first one relates to the initial compaction of the material to a specific pressure. Only in this form can it be pressed through the multi-holes die in order to shape the final geometric form. The pressed material has been modelled as elastic-plastic with a predefined hydrostatic pressure of the material arising from initial compaction. This pressure has been established on the basis of previous studies $[5,6]$ and its value has been set to $14 \mathrm{MPa}$. Due to insufficient information about the mechanical parameters of the precompacted carbon dioxide, which is to be pressed through the die, their values have been chosen so that the base convergent sleeve $(\mathrm{h}=7.5 \mathrm{~mm})$ can achieve a similar value of the force $F_{O P}$. The model calibrated in this way has been used only to determine the change trend of the force $F_{O P}$. In order to model the process of pressing the material through the die (the process of material delamination), the meshfree finite elements description method SPH (Smoothed Particle Hydrodynamics) - has been used. More information about this method can be found in [20]. Kinematic parameters of the process have been established with the same values as in [15]. Figure 10 shows the change of drag force $F_{O P}$ for the 
working unit, with the convergent sleeve height $\mathrm{h}=7.5 \mathrm{~mm}$. The chart applies only to the phase of pressing the pre-compacted material. Therefore, the characteristic change of force $F_{O P}$ corresponding to the initial compaction of the material is not visible in the chart. Figure 11 shows the change of drag force $F_{O P}$ for the working unit, with the convergent sleeve of height $\mathrm{h}=5 \mathrm{~mm}$. Figure 12 shows the change of drag force $F_{O P}$ for the working unit, with the convergent sleeve of height $h=10 \mathrm{~mm}$.

a)

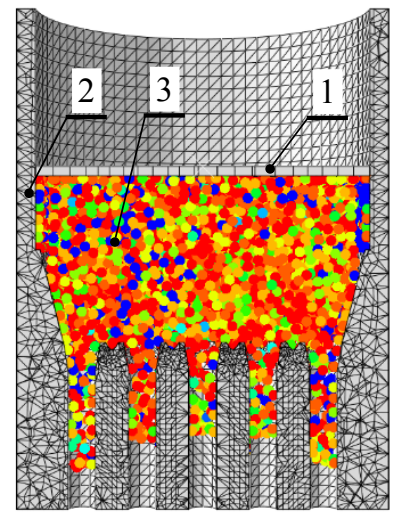

b)

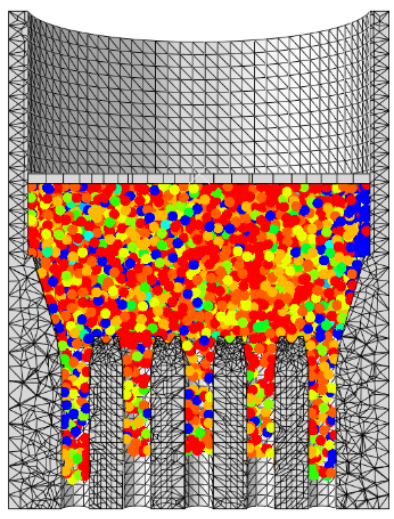

c)

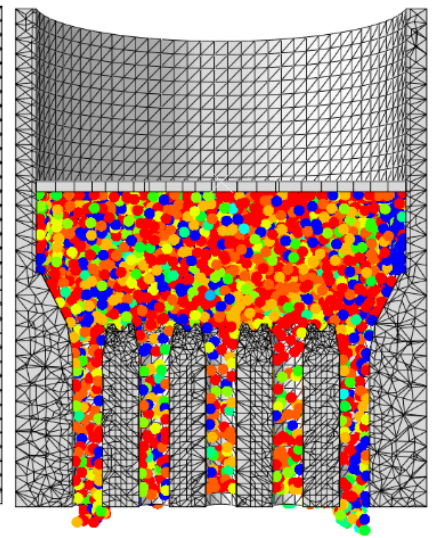

Fig. 9. FEM model of pressing pre-compacted dry ice through the multi-holes die: 1 - piston, 2 multi-holes die, 3 - pressed material a) convergent sleeve height $\mathrm{h}-10 \mathrm{~mm}, \mathrm{~b}$ ) convergent sleeve height $\mathrm{h}-7.5 \mathrm{~mm}, \mathrm{c})$ convergent sleeve height $\mathrm{h}-5 \mathrm{~mm}$

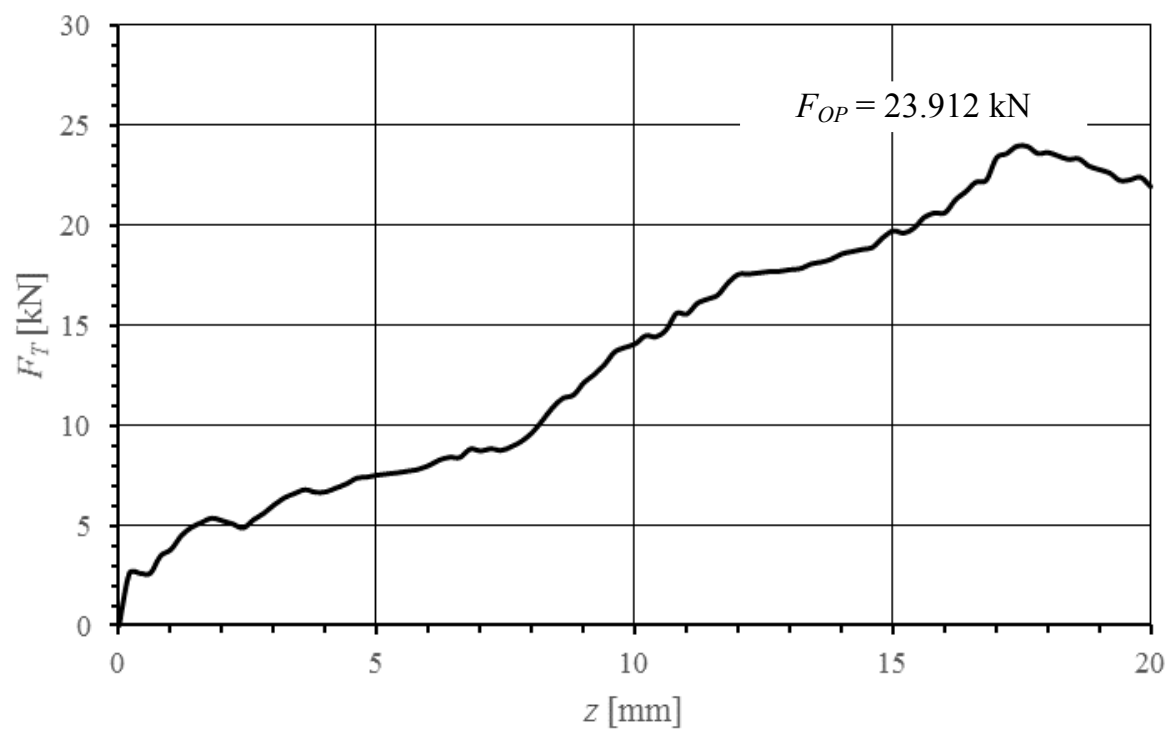

Fig. 10. Change of drag force $F_{O P}$ for the working unit with the convergent sleeve height $\mathrm{h}=7.5 \mathrm{~mm}$ 


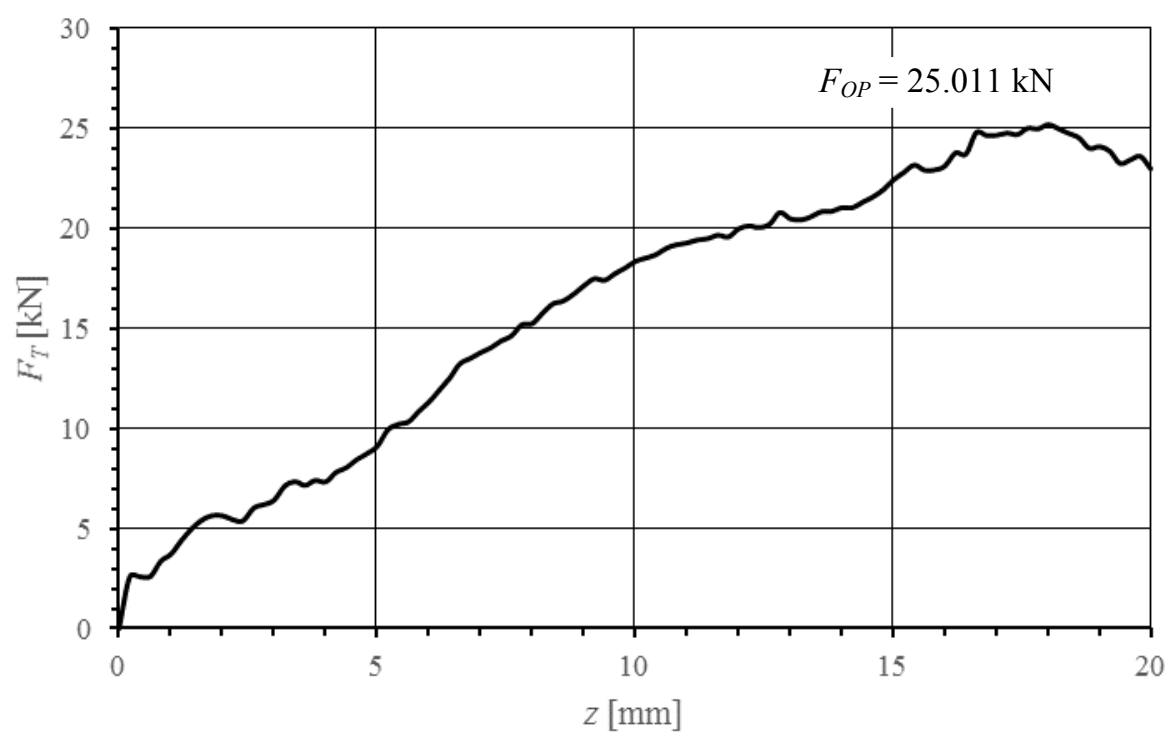

Fig. 11. Change of drag force $F_{O P}$ for the working unit with the convergent sleeve height $\mathrm{h}=5 \mathrm{~mm}$

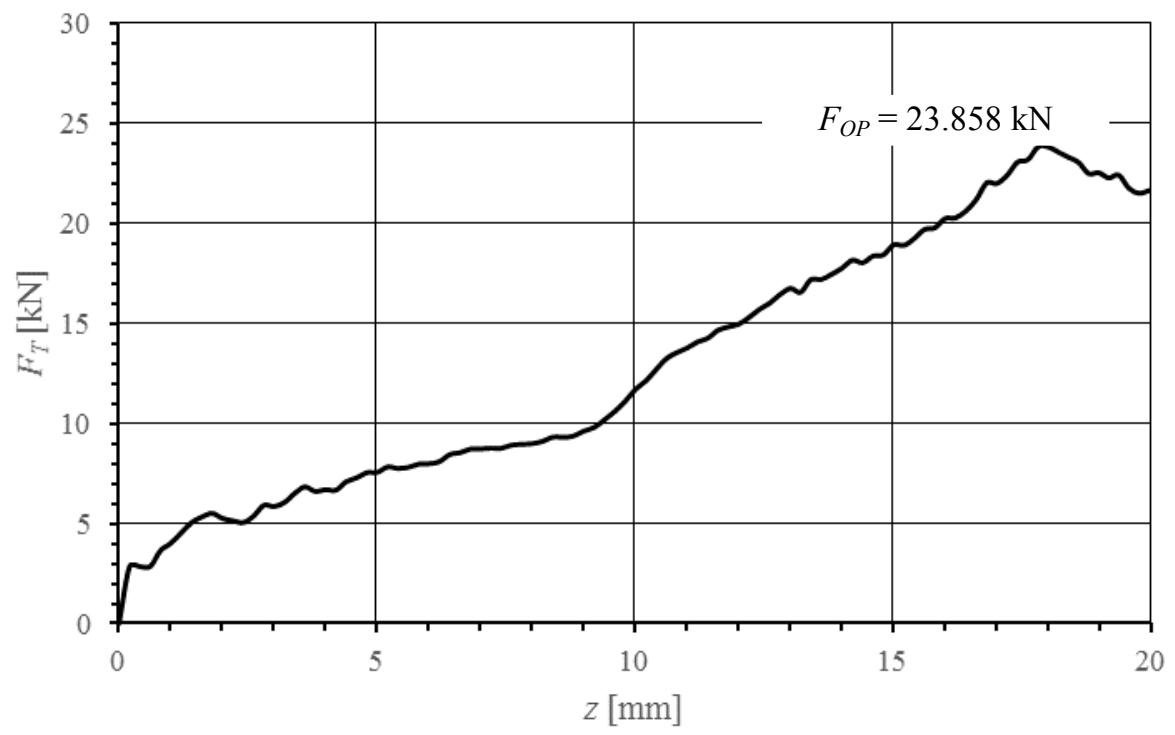

Fig. 12. Change of drag force $F_{O P}$ for the working unit with the convergent sleeve height $\mathrm{h}=10 \mathrm{~mm}$ 


\section{Influence of the sleeve height $h$ on the value of the force $F_{O P}$}

Based on the results of the numerical analysis, the initial characterization that describes the change in drag force $F_{O P}$ in the function of the convergent sleeve height $h$ has been formulated (fig. 13). The chart shows that the characterization in the range $h$ equal between 5 and $7.5 \mathrm{~mm}$ has a negative gradient value. After exceeding the $7.5 \mathrm{~mm}$ value it stabilizes and oscillates in the error range of the MES analysis in relation to the empirical study.

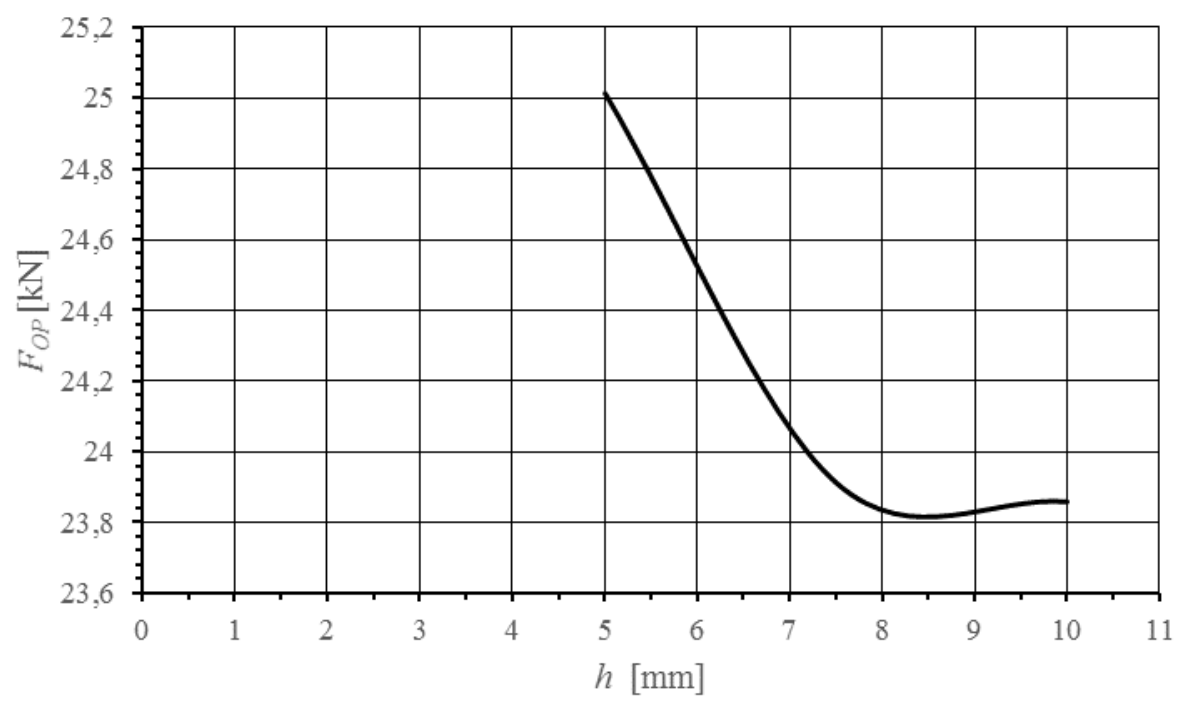

Fig. 13. Initial characterization of the changes to the drag force $F_{O P}$ in the function of the sleeve height $h$

\section{Conclusions}

On the basis of the performed empirical and numerical research, it was found that:

- reduction of the surface area $S_{P P}$ (fig. 3) has an impact on the value of drag force $F_{O P}$,

- the largest impact on the value of drag force $F_{O P}$ is observed in the sleeve height $h$ range from 5 to $7.5 \mathrm{~mm}$.

Deepening the current research can have a significant impact on the formulation of the assumptions for the machines for pressure agglomeration of crystallized $\mathrm{CO}_{2}$.

\section{References}

1. L. Chen, X. Zhang, A review study of solid-gas sublimation flow refrigeration: Form basic mechanism to applications. International Journal of Refrigeration 40, 61-83 (2014)

2. J. Vansant, Carbon dioxide emission and merchant market in the European union. In Aresta M. (eds) Carbon Dioxide Recovery and Utilization. Springer Science \& Business Media. (2013) 
3. Y. Liu, H. Maruyama, S. Matsusaka, Agglomeration process of dry ice particles produced by expanding liquid carbon dioxide. Advanced Powder Technology 21, 652657 (2010)

4. Y. Liu, G. Calvert, C. Hare, M. Ghadiri, S. Matusaka, Size measurement of dry ice particles produced form liquid carbon dioxide. Journal of Aerosol Science 48, 1-9 (2012)

5. Y. Liu, D Hirama D., Matusaka S., Particle removal process during application of impinging dry ice jet. Powder Technology 2017, 607-613 (2012)

6. V. Masa, P. Kuba, Efficient use of compressed air for dry ice blasting. Journal of Cleaner Production 111, 76-84 (2016)

7. A. Mazzoldi, T. Hill, J. Colls, $\mathrm{CO}_{2}$ transportation for carbon capture and storage: Sublimation of carbon dioxide from a dry ice bank. International Journal of Greenhouse Gas Control 2, 210-218 (2008)

8. E. Uhlmann, M. Kretzschmar, F. Elbing, V Mihotovic, Deburring with $\mathrm{CO}_{2}$ Snow Blasting. In: J. Aurich, D. Dornfeld (eds) Burrs - Analysis, Control and Removal. Springer, Berlin, Heidelberg

9. S. Dong, B. Song, B. Hansz, et al., Modeling of dry ice blasting and its application in thermal spray. Material Research Innovations 16, 61-66 (2012)

10. M. Li, W. Liu, X. Qing, et al., Feasibility study of a new approach to removal of paint coatings in remanufacturing. Journal of Materials Processing Technology 234, 102-112 (2016)

11. C. Otto, S. Zahn, F. Rost, et al., Physical Methods of cleaning And Disinfection of Surfaces. Food Engineering Review 3, 171-188 (2011)

12. G. Spur, E. Uhlmann, F. Elbing, Dry-ice blasting for cleaning: process, optimization and application. Wear 233-235, 402-411 (1999)

13. A. Witte, M. Bobal, R. David, et al., Investigation of the potential of dry ice blasting for cleaning and disinfection in the food production environment. LWT - Food Science and Technology 75, 735-741 (2017)

14. H. Yamaguchi, X. Niu, K. Sekimoto, P. Neksa, Investigation of dry ice blockage in an ultra-low temperature cascade refrigeration system using $\mathrm{CO}_{2}$ as a working fluid. International Journal of refrigeration 34, 466-475 (2011)

15. J. Górecki, I. Malujda, K. Talaśka, Research on Densification of solid carbon dioxide. Journal of Mechanical and Transportation engineering 65, 5-12 (2013)

16. J. Górecki, I. Malujda, K. Talaśka, Influence of the Value of Limit densification Stress on the Quality of Pellets During the Agglomeration Process of $\mathrm{CO}_{2}$. Procedia Engineering 136, 269-274 (2016)

17. Z. Drzymała, Basics of Compaction Engineering of Material Compaction (in polish), PWN, (1988)

18. Patent application No.: P.419432, Piston assembly designed for dry ice snow compression. (2016)

19. J. Górecki, I. Malujda, K. Talaśka, M. Kukla, P. Tarkowski, Investigation of internal friction of agglomerated dry ice. Procedia Engineering 136, 275-279 (2016)

20. Abaqus Documentation. Dassault Systemes, Paris, 2017 